\title{
Haemoglobin changes and risk of anaemia following treatment for uncomplicated falciparum malaria in sub-Saharan Africa
}

Julien Zwang ${ }^{1}$, Umberto D'Alessandro 2,3,4, Jean-Louis Ndiaye ${ }^{5}$, Abdoulaye A Djimdé ${ }^{6}$, Grant Dorsey ${ }^{7}$, Andreas A Mårtensson ${ }^{8,9}$, Corine Karema ${ }^{10,11}$ and Piero L. Olliaro ${ }^{11,12,13^{*}}$

\begin{abstract}
Background: Anaemia is common in malaria. It is important to quantitate the risk of anaemia and to distinguish factors related to the natural history of disease from potential drug toxicity.

Methods: Individual-patient data analysis based on nine randomized controlled trials of treatments of uncomplicated falciparum malaria from 13 sub-Saharan African countries. Risk factors for reduced haemoglobin ( $\mathrm{Hb})$ concentrations and anaemia on presentation and after treatment were analysed using mixed effect models.

Results: Eight thousand eight hundred ninety-seven patients ( $77.0 \%<5$ years-old) followed-up through 28 days treated with artemisinin combination therapy (ACT, 90\%, $n=7968$ ) or non-ACT. At baseline, under 5 's had the highest risk of anaemia ( $77.6 \%$ vs. $32.8 \%)$ and higher parasitaemia $(43,938 \mu \mathrm{l})$ than older subjects (2784 $\mu$ l). Baseline anaemia increased the risk of parasitological recurrence.

$\mathrm{Hb}$ began to fall after treatment start. In under 5's the estimated nadir was $35 \mathrm{~h}$ (range 29-48), with a drop of -12.8\% from baseline (from $9.8 \mathrm{~g} / \mathrm{dl}$ to $8.7 \mathrm{~g} / \mathrm{dl}, p=0.001$ ); in under 15 's, the mean $\mathrm{Hb}$ decline between day 0-3 was $-4.7 \%$ (from 9.4 to $9.0 \mathrm{~g} / \mathrm{dl}, p=0.001$ ). The degree of $\mathrm{Hb}$ loss was greater in patients with high pre-treatment $\mathrm{Hb}$ and parasitaemia and with slower parasite reduction rates, and was unrelated to age. Subsequently, Hb increased linearly $(+0.6 \% /$ day $)$ until day 28 , to reach $+13.8 \%$ compared to baseline.

Severe anaemia ( $<5 \mathrm{~g} / \mathrm{dl}$, 2 per 1000 patients) was transient and all patients recovered after day 14, except one case of very severe anaemia associated with parasite recurrence at day 28.

There was no systematic difference in $\mathrm{Hb}$ concentrations between treatments and no case of delayed anaemia.

Conclusion: On presentation with acute malaria young children with high parasitaemia have the highest risk of anaemia. The majority of patients experience a drop in $\mathrm{Hb}$ while on treatment as early as day $1-2$, followed by a linear increase through follow-up. The degree of the early $\mathrm{Hb}$ dip is determined by pre-treatment parasitaemia and parasite clearance rates. $\mathrm{Hb}$ trends and rick of anaemia are independent of treatment.
\end{abstract}

Keywords: P. Falciparum, Malaria, Artemisinin, Anaemia, Haemolysis, Artesunate, Amodiaquine, Sub-Saharan Africa

\footnotetext{
* Correspondence: olliarop@who.int

${ }^{11}$ University of Basel, Basel, Switzerland

${ }^{12}$ Special Programme for Research \& Training in Tropical Diseases (WHO/

TDR), 20 Avenue Appia, 1211 Geneva, Switzerland

Full list of author information is available at the end of the article
} 


\section{Background}

As anaemia is a common occurrence in malaria, it is often difficult, in treated patients, to disentangle disease from drug effects. Malaria anaemia has both central (decreased red cell production) and peripheral causes (haemolysis, phagocytosis of infected and uninfected erythrocytes) $[1,2]$. Artemisinin-based Combination Therapy (ACT) the treatment of choice for uncomplicated Plasmodium falciparum malaria [3] - is generally safe and well-tolerated, but anaemia remains a potential concern, in particular for artemisinin derivatives. In vitro experiments point to interference with erythropoiesis at the proerythroblast and basophilic erythroblast stage [4]. In humans, acute delayed haemolytic anaemia has been reported following artesunate injections in severe malaria [5], but not with ACT in uncomplicated falciparum malaria; transient anaemia has been reported in uncomplicated malaria after administration of artesunate, alone or as part of ACT [6-11], with a dosedependent risk [12]. As safety in general, and laboratory data in particular, are under-reported in antimalarial drug trials, limited information can be derived from aggregated data from the published literature. In particular anaemia, even when monitored, is variably reported as a continuous variable (haemoglobin concentration) or categorical variable (using different thresholds and severity classes).

This group therefore joined to create an individual participant-level database (IPD) of patients enrolled in studies conducted in Sub-Saharan Africa and applied a common, standardised analytical approach to quantify the risk of anaemia in patients presenting with acute, uncomplicated falciparum malaria, and analysed the changes in haemoglobin levels and anaemia status after treatment.

\section{Methods}

Data on age, parasitaemia, haemoglobin $(\mathrm{Hb})$, treatment and treatment outcome were extracted from primary data of nine randomized controlled trials (RCT) conducted in subSaharan Africa, of which seven had 28-day [13-20], and two had 42-day follow-up [20, 21]. The RCTs included in this paper were conducted to assess the efficacy and safety of different malaria treatment in sub-Saharan Africa using the WHO protocol (Zwang 2009, Zwang 2014). Data were censored when patients were lost to follow-up or had microscopy determined recurrent parasitaemia during follow-up.

Anaemia was defined and graded as per WHO, 2011 by age and sex [22] (Additional file 1: Table S1). Recovery from anaemia was defined as $\mathrm{Hb}$ increasing to levels above the aforementioned levels. Worsening of anaemia was any increase at any time in the grade of severity compared to pre-treatment (abnormal $\mathrm{Hb}$ in subjects with normal pre-treatment value, or an abnormal value that was of higher grade than pre-treatment). Drug-event relationship could not be attributed as it had not been assessed systematically across the clinical trials.
Treatments were artesunate-amodiaquine (ASAQ, as either fixed-dose or co-blister formulations) and comparators including artemisinin combination therapy (ACT: artemether-lumefantrine, AL; artesunate plus sulphadoxine/ pyrimethamine, AS + SP; dihydroartemisinin-piperaquine, $\mathrm{DP}$ ) or monotherapy (artesunate alone, AS; amodiaquine alone, $\mathrm{AQ}$ ) or non-artemisinin containing combinations $(\mathrm{AQ}+\mathrm{SP})$.

\section{Ethics}

All trials were conducted according to the Helsinki declaration and received approval by their respective ethics committees. These analyses are in accordance with the patient informed consent. Data were completely and irreversibly anonymised at the source before being shared and merged into the common database.

\section{Statistical analysis}

Categorical data (proportions of patients becoming or recovering from anaemia) were compared using the chi-square or the Fisher's exact test. For non-normally distributed data comparisons used the Mann-Whitney and the KruskallWallis tests and correlations, the Spearman test.

Definitions: D (Day) 0 = pre-treatment; $\operatorname{HDR}_{\mathrm{d} 1}(\mathrm{Hb}$ decrease rate $)=$ percentage difference in $\mathrm{Hb}$ concentration from $\mathrm{D} 0$ to $\mathrm{D} 1 ; \mathrm{PRR}_{\mathrm{d} 1}$ (parasite reduction rate) = percentage difference in parasite density from D0 to D1; PCT (parasite clearance time) $=$ time to reach a negative malaria smear for two consecutive days; nadir = the lowest $\mathrm{Hb}$ value at any time on-study; $\mathrm{T}_{\mathrm{n}}$ (time-to-nadir) = time at which the nadir was reached for each study subject.

All available $\mathrm{Hb}$ values for every patient were considered from D0 through D28. The risk of anaemia was assessed by mixed-effect logistic regression model to account for between-sites heterogeneity. The adjusted risks (AOR) allowed for patients' age, parasitaemia (log-transformed), parasitological recurrence, treatment and trial.

The risk of $\mathrm{Hb}$ dropping, resulting in anaemia at D3, or anaemia severity increasing, was analysed as a binary variable by mixed-effect logistic regression models. The percentage $\mathrm{Hb}$ decrease at nadir was analysed using mixed-effect linear regression models. $\mathrm{Hb}$ trends from D3 to D28 were assessed by a mixed-effect linear regression model and expressed as $y=a x+b$ (were $y, \mathrm{Hb} ; a$, slope; $x$, time; $b$, constant).

Confidence intervals were calculated at 95\% (95\%CI), and comparisons considered significant when $p<0.05$. Data were analysed using Stata v13 (Stata Corp.).

\section{Results}

Analyses were based on 8897 patients, $89.6 \%$ treated with an ACT and 10.4\% with non-ACTs (Additional file 2: Table S2, Additional file 3: Fig. S1), providing 38,864 $\mathrm{Hb}$ 
measurements $(93 \%$ and $7 \%$ for $\mathrm{ACT}$ and non-ACT, respectively).

Study characteristics are in Additional file 4: Table S3: 98\% ( $n=8728)$ of subjects had at least one other recorded value post-D0 ( $58 \%$ at D3, $80 \%$ at D7, $73 \%$ at D28); $18 \%(n=1645)$ children $<5$ years-old enrolled in Liberia, Mozambique, Rwanda and Uganda had daily measurements on D0 through D3; an additional 11\% $(n=1000)$ had daily measurements on D0 through D2. All but two studies (Uganda and Rwanda) had at least three measurements: D0, D28 and one in-between: D7 (11\%, in four countries), D14 (20\%, two countries), and D3, D7, and D14 (17\%, two countries).

Patients' baseline characteristics by study are in Table 1 and Fig. 1: $77 \%$ were children $<5$ years of age, $24.1 \%$ were $5-11$ years-old, $4.5 \%$ were $12-14$ years-old, and $11.0 \% \geq 15$. The geometric mean D0 parasite density was 13,790 overall, ranging from 594 (Liberia [19]) to 39,023 parasites/ $\mu \mathrm{l}$ (Mozambique [13]).

\section{Anaemia and haemoglobin levels on presentation with acute falciparum malaria}

Sixty-seven percent $(67.3 \%, n=5978 / 8897)$ of subjects had anaemia on D0, 63\% mild or moderate. The mean $\mathrm{D} 0 \mathrm{Hb}$ was $10.2 \mathrm{~g} / \mathrm{dl}$ (standard deviation 2.05) and the median $10.1 \mathrm{~g} / \mathrm{dl}$ (range 3.4-18.3).

$\mathrm{Hb}$ increased with age (from a median of $9.6 \mathrm{~g} / \mathrm{dl}$ in $<5$ years-old to $14.1 \mathrm{~g} / \mathrm{dl}$ in males $\geq 15$ years), corresponding to a decreasing prevalence of anaemia (from $77.6 \%$ to $22.1 \%$, respectively, Fig. 2).

A multivariate logistic regression model with mixed effects found that the risk of D0 anaemia decreased significantly with increasing age ( $p=0.001$ for all comparisons vs. under 5 's). Parasitological recurrence during follow-up was more frequent in subjects with D0 anaemia (AOR 1.45, 95\% CI 1.23-1.73, $p=0.001$ ).

Overall, higher D0 parasite density correlated with lower $\mathrm{Hb}$ by linear regression, mixed effect model (Fig. 3) except for $<5$ year-olds who had higher D0 geometric mean parasite densities $(43,938 \mu \mathrm{l})$ than older subjects $(2784 \mu \mathrm{l})$ (Additional file 5: Fig. S2).

\section{Anaemia during treatment and follow-up Occurrence of anaemia}

From D0 to last observation, $82.7 \%$ of the patients had at least one $\mathrm{Hb}$ measurement fulfilling the anaemia criteria (any grade of severity), corresponding to 26,408 (67.9\%) of the total $38,864 \mathrm{Hb}$ measurements; of these, 20,430 (77.4\%) occurred after treatment start (D1-D28). Moderate or more severe anaemia ( $\geq$ grade 2 ) occurred in $47.6 \%$ of all measurements $(18,486 / 38,864)$, in $76.5 \%$ of episodes $(14,148 /$ 18,486) after treatment start (D1-D28). Post-D0 anaemia was less frequent on ACT: all-grade ( $77.3 \%$ vs. $80.3 \%$, $p=0.036)$; $\geq$ grade 2 anaemia ( $76.4 \%$ vs. $81.1 \%, p=0.007)$.

\section{Severity of anaemia}

Five patients had very severe anaemia (grade 4) at D0. Overall, 19 patients had 27 records of transient very severe anaemia, corresponding to $2 / 1000$ patients (19/ 8897). All episodes of very severe anaemia occurred by D14 in ACT groups, corresponding to 1 per 1000 (27/ 26,408 ) of all anaemia episodes, with no difference between treatments. Only one patient had very severe anaemia on D28 concomitant with recurrent infection, while all other patients recovered after D14. No case of very severe anaemia was observed in patients treated with non-ACT.

\section{Changes in anaemia status}

Of the 8720 patients with at least one additional post-D0 $\mathrm{Hb}$ measurement, $67.9 \%$ were anaemic on presentation and $47.1 \%$ when last seen - the latter was composed of 41.9\% who remained anaemic plus an additional 5.2\% who became anaemic post-D0. Anaemia grade worsened in $31.9 \%$ patients.

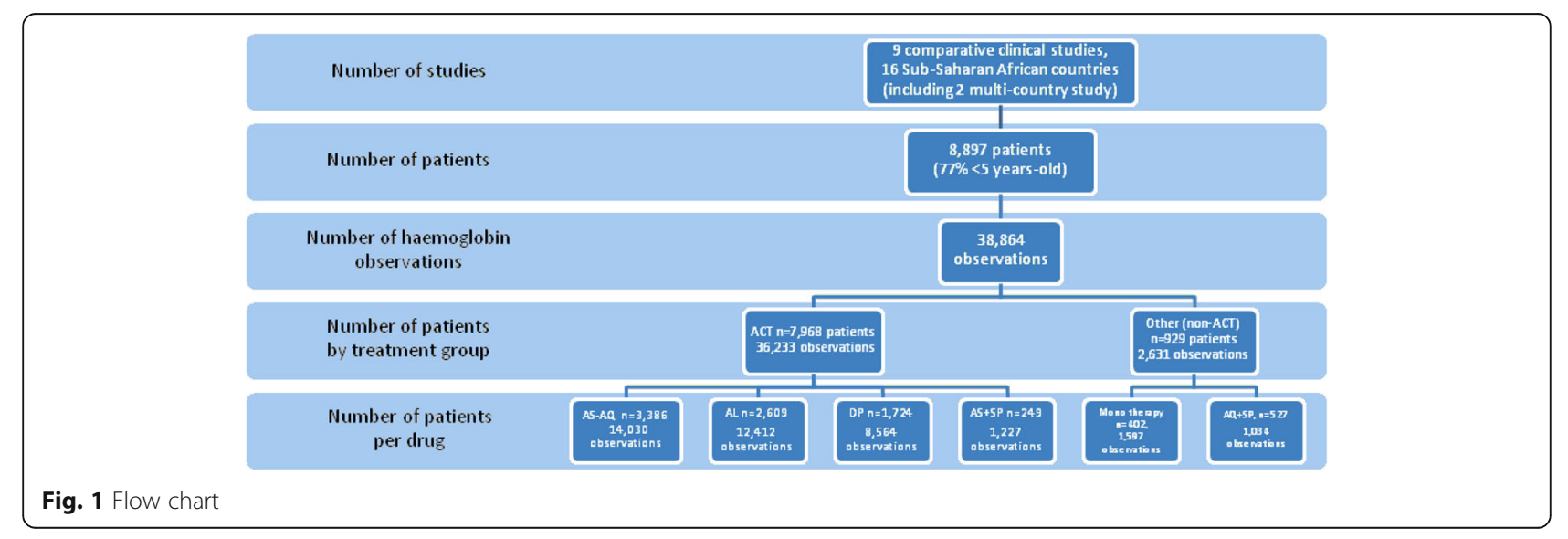




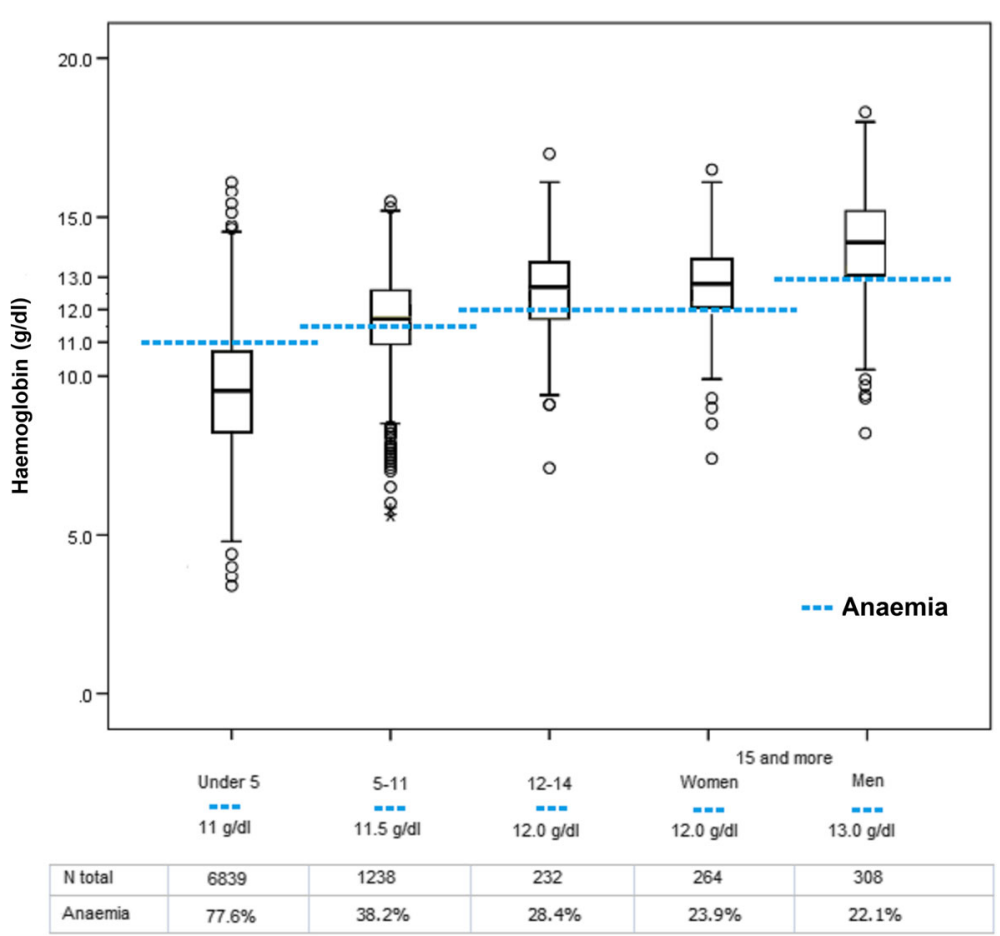

Age categories (year)

Fig. 2 Boxplot of haemoglobin concentration values pre-treatment (D0) by age and sex category. The dotted blue line represents the anaemia-defining $\mathrm{Hb}$ value for each category

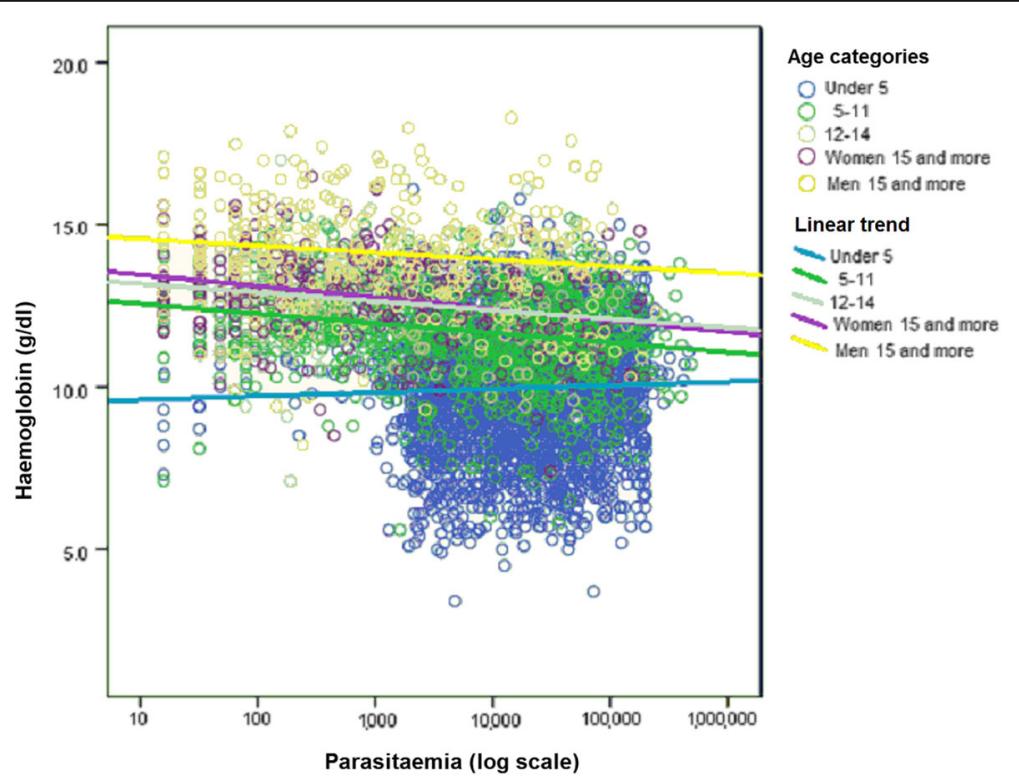

Fig. 3 Scatter plot of haemoglobin concentration values and parasitaemia pre-treatment (D0): overall and by age and sex category. AOR for 5-11 yearsold of 0.51 (95\% Cl 0.41-0.62); 12-14 AOR $0.41(0.28-0.60) ; \geq 15$ AOR $0.27(0.20-0.37)$. For the whole study population the equation calculated by linear regression with mixed effect model was $y=-0.06 x+10.3, p=0.020$ 
Mixed-effect multivariate logistic regression model showed an increased risk of anaemia worsening in patients with higher D0 parasitaemia (AOR 1.65, 95\% CI 1.52-1.79, $p=0.001$ ) and $\mathrm{Hb}$ (AOR 1.57, 95\% CI 1.51-1.63, $p=0.001$ ), younger age (AOR 0.95, 95\% CI 0.94-0.97, $p=0.001$, per year of age). It detected no significant association with parasitological failure (AOR 0.94, 95\% CI $0.81-1.12, p=0.452$ ) and no difference between treatments, except a lower risk with AQ + SP (AOR 0.51, 95\% CI 0.36-0.72, $p=0.001)$ compared to ASAQ.

\section{Haemoglobin levels during treatment and follow-up Haemoglobin levels changes (D0 - D3 - D28)}

Ten countries and 15 sites (Burkina Faso, Gabon, Liberia, Mali, Mozambique, Nigeria, Rwanda, Uganda, Zambia, Zanzibar) had $\mathrm{Hb}$ measurements on D0, D3 and then weekly from D7-D28 $(n=4886$ inclusive of the 1645 above; median age 2 years, range 6 months to 14 years). Between D0 and D28, Hb increased by $+13.8 \%$ (from 9.4 to $10.7 \mathrm{~g} / \mathrm{dl}$ ).

\section{Haemoglobin levels changes between D0 and D3}

On D3, Hb concentrations decreased $-4.6 \%$ (95\% CI $-4.3 \%$ to $-4.9 \%$ ), from 9.4 to $9.0 \mathrm{~g} / \mathrm{dl}$; such decrease was of $-4.5 \%$ (95\% CI $-.2 \%$ to $-4.8 \%$ ), from 9.3 to $8.9 \mathrm{~g} / \mathrm{dl}$, in patients treated with ACT and $-7 \%$ (95\% CI -8.5\%-5.6\%) on AS. The D3 drop in $\mathrm{Hb}$ was greater for subjects with normal D0 $\mathrm{Hb}$ (from 11.9 to $10.8 \mathrm{~g} / \mathrm{dl},-9.3 \%, 95 \% \mathrm{CI}-9.9 \%$ to $-8.6 \%$ ) than for those who were anaemic (from 8.9 to $8.6 \mathrm{~g} / \mathrm{dl},-3.4 \%, 95 \% \mathrm{CI}-3.7 \%$ to $-3.0 \%, p=0.001)$.

A multivariate logistic regression model with mixedeffect showed that the risk was higher for patients with higher D0 parasitaemia (AOR 2.51, 95\% CI 2.23-2.83, $p=0.001)$ and $\mathrm{Hb}$ (AOR 1.19, 95\% CI 1.14-1.24, $p=0.001$ ) and lower for older subjects (AOR 0.87, 95\% CI $0.83-0.92, p=0.001$ ), while no significant association was found with parasitological failure (AOR 1.13, 95\% CI 0.95$1.34, p=0.177$ ) and treatment (all comparisons $p>0.1$ ).

\section{Time to haemoglobin nadir, children $<5$ years-old}

Two studies enrolled 1645 children $<5$ years-old (median age 2.3 years, range 0.5-4.9) in Liberia [19], Mozambique, Rwanda, and Uganda [13] and recorded Hb on D0-D3, D7, D14, D21, D28. D0 parasite density was 23,908 / $\mu \mathrm{l}$ overall but varied across sites $(p=0.001)$. Median time-tonadir (Tn) was D2 Table 2), and was independent of treatment (all comparisons $p>0.1$ ). The predicted median $\mathrm{T}_{\mathrm{n}}$ calculated by linear regression was $35 \mathrm{~h}$, ranging from $29 \mathrm{~h}$ with ASAQ in Uganda to $48 \mathrm{~h}$ with DP in Rwanda (Additional file 6: Fig. S3).

The nadir occurred in $78 \%$ between D1-3, with the highest proportion on D2 (34\%). The highest rate of $\mathrm{Hb}$ decrease $(-12.6 \%)$ and slope $(-1.25)$ were at D1. The $\mathrm{PRR}_{\mathrm{d} 1}$ was highest $(98.4 \%)$ for the patients whose $\mathrm{Hb}$ increased post-D0 (HDR $\left.{ }_{\mathrm{d} 1}+8.3 \%\right)$ and lowest $(83.8 \%)$ in those with nadir at $\mathrm{D} 3\left(\mathrm{HDR}_{\mathrm{d} 1}-1.8 \%\right)$. Excluding the $11 \%$ subjects with no decrease, overall $\mathrm{Hb}$ dropped from $9.8 \mathrm{~g} / \mathrm{dl}$ to $8.7 \mathrm{~g} / \mathrm{dl}(-1.18 \mathrm{~g} / \mathrm{dl}$ or $-11.4 \%$, 95\% CI $-11.0 \%$ to $-11.8 \%, p=0.001$ ) (Table 2). The patterns of evolution of $\mathrm{Hb}$ levels are shown in Additional file 7: Fig. S4.

Subjects whose $\mathrm{Hb}$ increased after baseline (nadir on D0) had significantly lower D0 parasitaemia $(14,410 \mu \mathrm{l})$ and $\mathrm{Hb}(9.0 \mathrm{~g} / \mathrm{dl})$ than those whose $\mathrm{Hb}$ decreased postD0 (parasite density $=25,403 / \mu \mathrm{l} ; \mathrm{Hb}=9.9 \mathrm{~g} / \mathrm{dl}, p=0.001$ ). Subjects with higher D0 parasitaemia had longer $\mathrm{T}_{\mathrm{n}}$ $(r=0.281, p=0.001$, Spearman test); the correlation between parasitaemia and $\mathrm{T}_{\mathrm{n}}$ occurring between D1 and D7 was also significant $(r=0.060, p=0.021$, Spearman test) (Fig. 4). $\mathrm{T}_{\mathrm{n}}$ was longer, and the drop in $\mathrm{Hb}$ greater, in patients without D0 anaemia (mean $\mathrm{T}_{\mathrm{n}} 3.0$ days; $\mathrm{Hb}$ change -14.7 ) than those presenting with anaemia (mean $\mathrm{T}_{\mathrm{n}} 2.1$ days; $\mathrm{Hb}$ change $-10.4 \%, p=0.001$ ). The PCT (but not PRRd1) of patients whose $\mathrm{Hb}$ increased right after treatment start was significantly faster $(p=0.001)$ than that of patients with a decrease in $\mathrm{Hb}$ (whatever the time to nadir); no difference was apparent for either parameters between the groups with shorter and longer time to nadir.

Different approaches using linear regression mixedeffect multivariate analyses produced consistent results, whether the model includes the $\mathrm{PRR}_{\mathrm{d} 1}$, PCT or HDR $\mathrm{H}_{\mathrm{d} 1}$. The $\mathrm{Hb}$ percentage decrease at $\mathrm{T}_{\mathrm{n}}$ was greater in subject with higher $\mathrm{D} 0 \mathrm{Hb}$ and parasitaemia $(p=0.001)$ and those with longer PCT $(p=0.001)$, and smaller in those with higher $\mathrm{PRR}_{\mathrm{d} 1}$. A slight difference between models was that the $\mathrm{Hb}$ percentage decrease was independent of age when $\mathrm{PRR}_{\mathrm{d} 1}$ is used in the model $(p=0.088)$ but lower in older patients $(p=0.010)$ when using PCT. It was lower in patients treated with AL or DP than ASAQ ( $p=0.001$ in all comparison except DP when using PCT, $p=0.070)$.

Special attention was paid to the interaction between $\mathrm{Hb}$ and parasitaemia at D1 (when on average 93\% of the parasites were cleared - see Table 2). The rate at which $\mathrm{Hb}$ fell (measured as $\mathrm{Hb}$ decrease rate from D0 to $\mathrm{D} 1, \mathrm{HDR}_{\mathrm{d} 1}$ ) was slower in patients with longer $\mathrm{T}_{\mathrm{n}}$ and faster in patients with higher $\mathrm{D} 0 \mathrm{Hb}(p=0.001)$. Concerning parasitaemia, $\mathrm{HDR}_{\mathrm{d} 1}$ was higher in patients with higher D0 parasitaemia $(p=0.001)$, and those with longer $\operatorname{PCT}(p=0.001)$, but was unrelated to $\operatorname{PRR}_{\mathrm{d} 1}$ $(p=0.112)$ and age $(p=0.296$ and $p=0.124$ in either models). $\mathrm{HDR}_{\mathrm{d} 1}$ was less in patients treated with $\mathrm{AL}$ or DP than with ASAQ $(p=0.001)$.

\section{Haemoglobin recovery post-treatment}

After an initial decrease in Hb concentrations, a $+19.4 \%$ increase from D3 to D28 (from 8.9 to $10.7 \mathrm{~g} / \mathrm{dl}$ ) was observed with a steady significant linear increment in $\mathrm{Hb}$ of $+0.065 \mathrm{~g} / \mathrm{dl} /$ day throughout D28, i.e. $+0.6 \%$ daily 


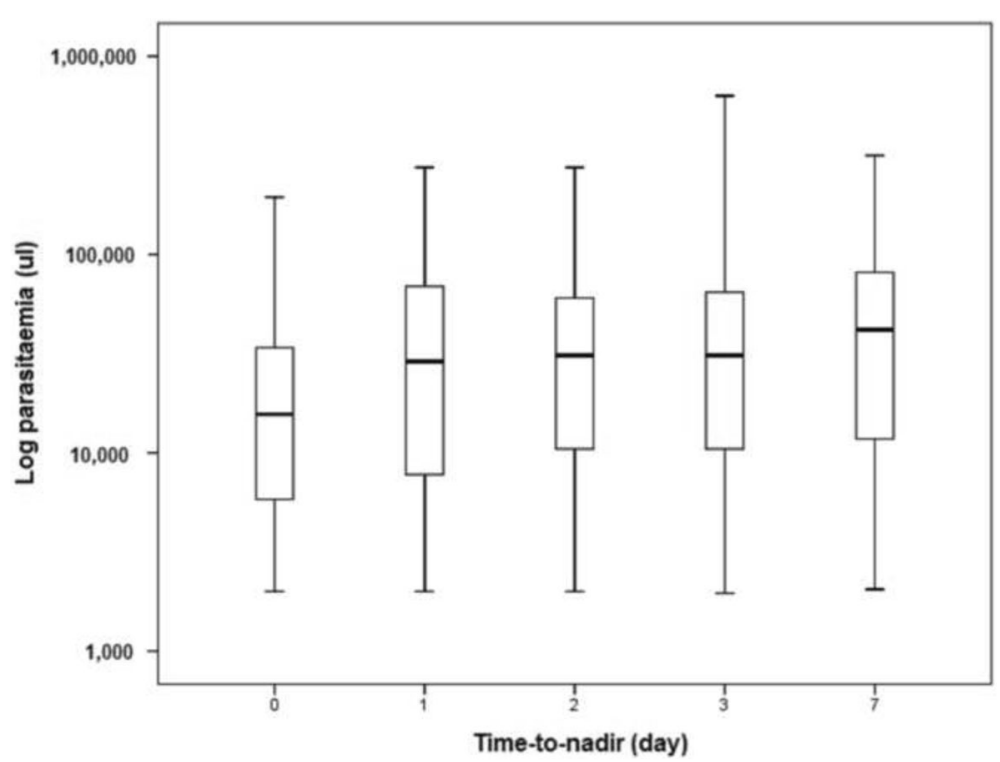

Fig. 4 Parasite density pre-treatment (D0) and time-to-nadir, children under 5 years old (Liberia, Mozambique, Rwanda, Uganda; $n=1645$ )

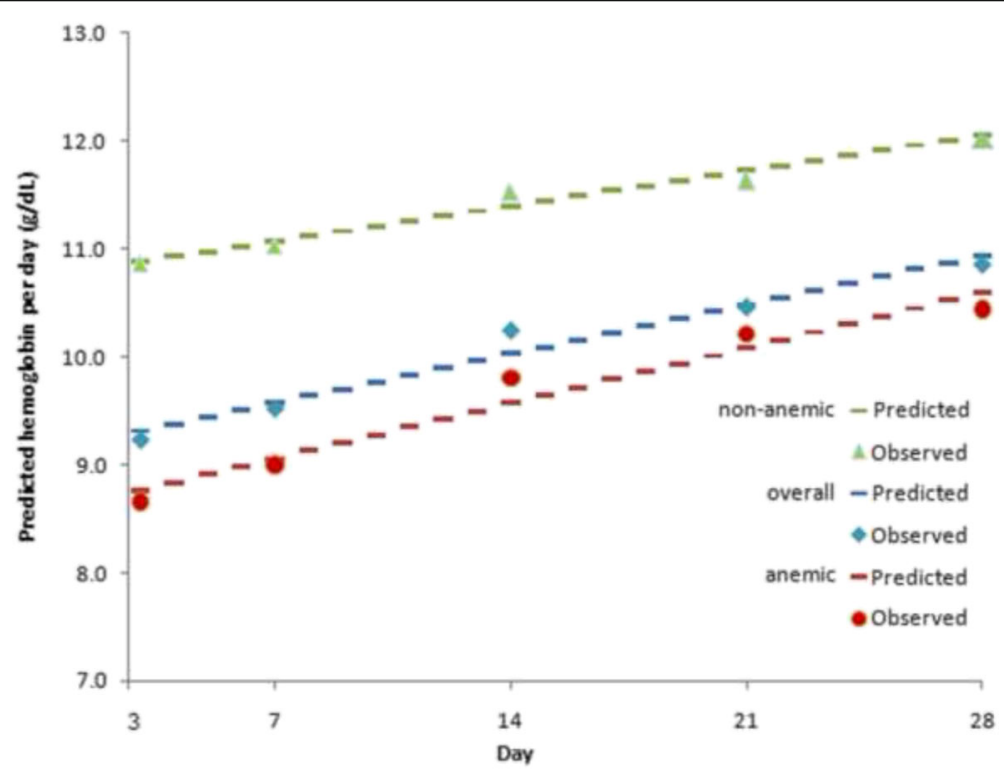

Fig. 5 Day 3 to Day 28, overall predicted trend and observed haemoglobin values according to anaemia status on admission, children under 15 years old (Burkina Faso, Gabon, Liberia, Mali, Mozambique, Nigeria, Rwanda, Uganda, Zambia, Zanzibar; $n=4886$ ) Equations

Overall: $y=0.065 x+9.1, p=0.001$

By anaemia status:

- anaemia on D0 y $=0.073 x+8.5, p=0.001$

- no anaemia on D0 $y=0.047 x+10.4, p=0.001$

By age (not shown):

- under 5's $y=0.71 \times+8.8, p=0.001$ 
(Fig. 5). Patients with normal D0 Hb levels experienced a significant slower recovery $(+0.047$ vs. $+0.073 \mathrm{~g} / \mathrm{dl} /$ day, $p=0.001$; corresponding to a daily $\mathrm{Hb}$ increase of $+0.4 \%$ and $+0.7 \%$, respectively) than those with pre-treatment anaemia.

Linear regression mixed-effect model found that the recovery in under 5 's was not significantly different from the 5-15 years-old ( $p=0.059)$, but that it was significantly faster in patients with anaemia on D0 than those without anaemia $(p=0.001)$. No between-treatment difference was detected.

\section{Discussion}

While anaemia is a common feature of uncomplicated falciparum malaria, studying anaemia during and after malaria treatment is challenging because it is difficult to disentangle the contributions of the infection itself, the process of recovering from the disease, and drug-induced adverse events. Furthermore, $\mathrm{Hb}$ is measured inconsistently across antimalarial drug trials during treatment and follow-up, and sometimes not often enough to describe with sufficient precision the patterns of $\mathrm{Hb}$ changes. Lastly, the definition and grades of anaemia may vary across studies. All this calls for more standardised study methodologies.

This analysis, representing a wide range of different geographical areas of Sub-Saharan Africa (nine studies at 24 sites in 13 countries), concerns nearly 9000 patients (of whom three-quarters are children under 5 years of age) treated with either ACT or non-ACT for uncomplicated falciparum malaria. Although the frequency of sampling during the study varied, $\mathrm{Hb}$ changes resulting in anaemia could be studied during treatment and follow-up and could be compared between treatments. Data were analysed both as continuous (Hb concentration) and categorical variable (age-dependent presence and grade of anaemia [22]), and risk factors for anaemia and drop in $\mathrm{Hb}$ concentrations were assessed.

\section{Anaemia risk on presentation with an acute uncomplicated falciparum malaria episode}

Anaemia was common in this largely paediatric patient population: over two-thirds presented with anaemia, and as many as $83 \%$ had at least one on-study $\mathrm{Hb}$ value below the anaemia-defining cut-off.

Comparing these results between this dataset and other published studies is difficult, as different cut-offs were used to define anaemia and some studies report mean or median $\mathrm{Hb}$ levels but not anaemia prevalence. Drawing generalizable conclusions is further complicated by the absence of information on background intensity of transmission and other conditions which may cause $\mathrm{Hb}$ to fall. For instance, considering recent studies, using $\mathrm{Hb}<11 \mathrm{~g} / \mathrm{dl}$ as the general cut-off, the prevalence of anaemia was $36 \%$ in Mali in all-ages subjects with acute malaria $(n=5990)$ with a geometric mean of $\sim 18,000$ parasites/ $\mu \mathrm{l}[23]$. When using haematocrit $<30 \%(\sim \mathrm{Hb}<10 \mathrm{~g} / \mathrm{dl})$ in a cohort of 672 Nigerian $<5$ 's with acute malaria, anaemia was found in $44 \%$ of subjects [24]. Other studies report median $\mathrm{Hb}=8.6 \mathrm{~g} / \mathrm{dl}$ ( $>5000$ children $<11$ yearsold, mean parasitaemia 9500 parasites/ $\mu$ l in Gabon) [25]; mean $\mathrm{Hb}=10.6 \mathrm{~g} / \mathrm{dl}$ (>900 children $<6$ years-old, mean parasitaemia $\sim 40,000$ parasites/ $\mu$ l in Mali) [26]; mean $\mathrm{Hb}=0.7 \mathrm{~g} / \mathrm{dl}(\sim 800$ children $<10$ years-old, mean parasitaemia 1250 parasites/ $\mu$ in Zambia) [27]; mean $\mathrm{Hb}=9.9 \mathrm{~g} / \mathrm{dl}-10.4 \mathrm{~g} / \mathrm{dl}$ (children $<11$ years-old, median parasitaemia $\sim 14,000$ parasites/ $\mu$ l in Cameroon) [28]. Even within the present analysis we found wide inter-country variations, with pre-treatment prevalence of anaemia ranging from $2.3 \%$ (in Liberia where patients had lower parasitaemia [19]) to $80.1 \%$ in Zanzibar, [21], and mean pre-treatment $\mathrm{Hb}$ from $8.6 \mathrm{~g} / \mathrm{dl}$, Zanzibar [21] to $12.9 \mathrm{~g} / \mathrm{dl}$ in Liberia [19].

While malaria is known to cause anaemia, the extent of $\mathrm{Hb}$ loss caused by each individual episode in not well quantified. In a previous paper [29] we estimated this drop to average $1.2 \mathrm{~g} / \mathrm{dl}$ or $13 \%$ of a subject "normal status".

Not unexpectedly, young age was found to be a risk factor for anaemia on presentation with acute falciparum malaria: compared to circa three-quarters of the under 5 's presented with anaemia, the relative risk was reduced by half to two-thirds in older subjects. There was a significant inverse correlation between parasitaemia and $\mathrm{Hb}$ concentrations overall.

\section{The fall and rise of haemoglobin}

$\mathrm{Hb}$ drops soon after treatment starts to reach its nadir $(-4 \%$ to $-6 \%)$ between D1-D3, thus supporting the use of the latter as proxy for maximum $\mathrm{Hb}$ fall in the standard clinical trial. Thereafter $\mathrm{Hb}$ increases at a steady rate of ca. $0.6 \%$ per day. Patients with normal D0 Hb levels experience a greater fall (-6\% vs. $-3.1 \%)$ and slower recovery $((+0.4 \%$ and $+0.7 \%$ per day, respectively) than those with pre-treatment anaemia. This study found no evidence of delayed anaemia associated with oral artemisinin derivatives, or any other treatment; in fact, the risk of anaemia decreased with follow-up time.

This general trend hides three patterns of evolution of $\mathrm{Hb}$ concentrations which become apparent in under 5's undergoing intense monitoring: (a) the dominant response $(\sim 78 \%)$ is a decrease with the lowest $\mathrm{Hb}$ level recorded between D1 and D3. This appears to be a fairly homogeneous population with D0 parasitaemia $\sim 25,000$ parasites/ $\mu \mathrm{l}, \mathrm{PCT} \sim 30 \mathrm{~h}$ [30], Hb 9.7-9.9 mg/dl, and drop at nadir -11.1 to $-13.4 \%$; (b) an additional $12 \%$ had their $\mathrm{Hb}$ nadir at their $\mathrm{D} 7$ visit; they had higher pretreatment parasite counts $(\sim 30,000)$ and $\mathrm{Hb}(10.7 \mathrm{~g} / \mathrm{dl})$ but their final $\mathrm{Hb}$ drop was only marginally greater 
$(-13.8 \%)$; (c) in a further $11 \%$ of these patients $\mathrm{Hb}$ started climbing immediately after treatment commenced $(+8.3 \%$ on D1); they had lower D0 parasite counts and $\mathrm{Hb}$ than those whose $\mathrm{Hb}$ fell after treatment start. So, both pretreatment $\mathrm{Hb}$ and parasite counts were (b) $>$ (a) $>$ (c), whereas the final $\mathrm{Hb}$ concentrations were (c) $>$ (a) $>$ (b). Patients whose $\mathrm{Hb}$ started to increase immediately with treatment cleared their parasites faster: the PCT was (c) $>$ (a) $=($ b) .

How are these different patterns explained, and how could they help us understand the relative effects on $\mathrm{Hb}$ of uncomplicated falciparum malaria and antimalarial treatment? We do not have all the elements to help us draw definitive conclusions. For instance we do not know how long had the patients been infected, and what the time-course of their $\mathrm{Hb}$ level had been before they came into observation. We know that malaria-induced anaemia is accounted for not only by the destruction of parasitized RBCs but also by the removal of uninfected RBCs and by central effects on erythropoiesis. If already on a downwards trend before treatment, $\mathrm{Hb}$ is therefore expected to continue to fall because some of these events will continue even when parasites are being killed by the treatment. In fact, parasite killing accounts for a small proportion of the $\mathrm{Hb}$ loss. Take for instance patients whose nadir was on D1 (D0 parasitaemia $=23,221 / \mu \mathrm{l}$; $\mathrm{PRR}_{\mathrm{d} 1}=95.4 \%, \mathrm{HDR}_{\mathrm{d} 1}-12.6 \%, \mathrm{Hb}$ drop $\left.-1.27 \mathrm{~g} / \mathrm{dl}\right)$, and assuming the $\mathrm{MCH}$ (mean cell $\mathrm{Hb}$ ) to be 25 picograms $\left(=2.5^{-11} \mathrm{~g} / \mathrm{RBC}\right)$, a $\mathrm{PRR}_{\mathrm{d} 1}=95.4 \%$ would translate in a loss of $2.229 \mathrm{RBCs} / \mathrm{dl}$ and $0.055 \mathrm{Hb} \mathrm{g} / \mathrm{dl}$. This means that $96 \%$ of the total $1.27 \mathrm{~g} / \mathrm{dl} \mathrm{Hb}$ drop is unaccounted for by parasite killing (RBC destruction); this difference would remain very large even after allowing for the biomass of sequestered parasites which are not seen in the peripheral circulation. The total loss in RBCs (as calculated from the drop in $\mathrm{Hb}$ ) is approximately 20 times that accounted for by parasite clearance. The early $\mathrm{Hb}$ drop and the absence of delayed anaemia reported in cases of severe malaria treated with artesunate [31], makes the contribution of 'pitting' (removal of 'once-infected erythrocytes' by the spleen) in the case of uncomplicated malaria unlikely or unimportant, possibly because of the relatively lower parasite counts in uncomplicated malaria.

The malaria parasite is likely to determine the presence and degree of anaemia both directly by the abovementioned central and peripheral parasite effects, and also indirectly for example by inducing, through generalised vasodilation and internal fluid redistribution, complex changes in fluid balance resulting in the reduction of the effective circulating blood volume [32], which are corrected during recovery. It is therefore possible that, since what we measure is concentrations and not absolute numbers, we have an incomplete picture of the real situation in terms of both anaemia on presentation and recovery post-treatment.
Our analyses point to a correlation between parasite clearance and changes in $\mathrm{Hb}$ levels. Linear regression mixed-effect multivariate analysis using different approaches concur to show that the degree of $\mathrm{Hb}$ loss after treatment start is greater in patients with high pre-treatment $\mathrm{Hb}$ and parasitaemia, is overall unrelated to age, whether measured at $\mathrm{D} 1$ as $\mathrm{Hb}$ decrease rate $\left(\mathrm{HDR}_{\mathrm{d} 1}\right.$, approximately $24 \mathrm{~h}$ after treatment started) or at the time of nadir as percentage decrease from pretreatment values. The drop in $\mathrm{Hb}$ levels is greater in patients with slower parasite clearance and it is smaller as percent reduction at nadir in those with higher parasite clearance on $\mathrm{D} 1$. The early $\mathrm{Hb}$ fall seems therefore to be more a question of slower onset of drug action than it is of drug toxicity, is a short-term event, and is independent of treatment ultimately succeeding or failing or of patient's age.

\section{Conclusions}

This study clarifies issues about risk factors of anaemia in uncomplicated falciparum malaria before and after treatment. It identifies risk factors on presentation (young age, high parasitaemia), detects different patterns of responses following antimalarial treatment (immediate increase, or early or late decline followed by a linear increase afterwards to restore normal $\mathrm{Hb}$ concentrations), shows that the majority of subjects experience a drop within 1-2 days (thus earlier than commonly thought), and finds a relationship between the degree of the early $\mathrm{Hb}$ dip and slower parasite clearance. However, we still have an incomplete picture of the overall interaction between malaria infection, antimalarial treatment and anaemia risk, especially when it comes to the explaining the complex relationship between infection, treatment and haemoglobin.

\section{Additional files}

Additional file 1: Table S1. Anaemia grades ( $\mathrm{g} / \mathrm{dl}$ ) of severity according to age and sex. (DOCX $14 \mathrm{~kb}$ )

Additional file 2: Table S2. Breakdown by treatment. (DOCX 14 kb) Additional file 3: Figure S1. Number of patients by treatment. AS, artesunate; $A Q$, amodiaquine; $A S A Q$, artesunate-amodiaquine; $A L$, artemether-lumefantrine; DP, dihydroartemisinin-piperaquine; SP, sulphadoxine-pyrimethamine. (TIFF $1276 \mathrm{~kb}$ )

Additional file 4: Table S3. Study characteristics: number of $\mathrm{Hb}$ measurements (total and by treatment) and measurement days. (DOCX $17 \mathrm{~kb}$ )

Additional file 5: Figure S2. Scatter plot of haemoglobin concentration values and parasitaemia pre-treatment (D0): overall and by age and sex category. For the whole study population the equation calculated by linear regression with mixed effect model was $y=-0.06 x+10.3, p=0.020$ (overall), $y=0.08 x+9.30, p=0.021$ (children $<5$ years-old) and $y=-$ $0.21 \times+12.4, p=0.001$ (subjects of 5 years of age or more). (TIFF $4286 \mathrm{~kb}$ )

Additional file 6: Figure S3. Predicted median time-to-nadir by country and treatment group, children under 5 years of age (Liberia, Mozambique, Rwanda, Uganda; $n=1645$ ). ASAQ, artesunate-amodiaquine; $A L$, artemether- 
lumefantrine; DP, dihydroartemisinin-piperaquine: Parasite density was expressed in geometric mean ( $\mu$ l). (TIFF $2364 \mathrm{~kb}$ )

Additional file 7: Figure S4. Mean haemoglobin values according to each patient's anaemia status on admission, children under 5 years old (Liberia, Mozambique, Rwanda, Uganda; $n=1645$ ). (TIFF 1913 kb)

\section{Abbreviations}

ACT: Artemisinin combination therapy; AL: Artemether-lumefantrine; AOR: Adjusted risks; AQ: Amodiaquine; AS: Artesunate; AS + SP: Artesunate plus sulphadoxine/pyrimethamine; Cl: Confidence intervals; DP: Dihydroartemisininpiperaquine; Hb: Haemoglobin; HDRd1: Haemoglobin decrease rate by Day 1; IPD: Individual participant-level database; PCT: Parasite clearance time; PRRd1: Parasite reduction rate by Day 1; RCT: Randomized controlled trials; $T_{n}$, time-to-nadir

\section{Acknowledgements}

Heartfelt thanks to Lucio Luzzatto for critically reviewing the manuscript. We thank all the participants in the cohorts used in this study and also the research teams involved. PO is a staff member of the WHO; the authors alone are responsible for the views expressed in this publication and they do not necessarily represent the decisions, policy or views of the WHO.

\section{Funding}

JZ received a grant from TDR (UNICEF/UNDP/WB/WHO Special Programme for Research \& Training in Tropical Diseases) and DNDi (Drugs for Neglected Diseases initiative) to do this analysis. DNDi is an independent, not-for-profit product development partnership working to research and develop new and improved treatments for neglected diseases. DNDi sponsored two of the trials but had no role in the design and conduct of the analysis, interpretation of results of the manuscript.

The Mali study was supported by European and Developing Countries Clinical Trial Partnership (EDCTP) fellowship [Grant to AAD \# 2004.2.C.f1] and by Sanofi Aventis [ARTEN-L-00848] who provided the monitoring services, the study insurance, the study drugs and the biological parameters assessment machines.

\section{Availability of data and materials}

All data supporting our findings can be found in all the respective publications of the studies included in the analysis.

\section{Authors' contributions}

The corresponding author had full access to all the data and had final responsibility for the decision to submit for publication. JZ, PO designed the analysis, interpreted the data and prepared the manuscript; JZ pooled and analysed the data. All authors (JZ, UA, JLN, AAD, GD, AM, CK, PLO) read and approved the final manuscript

\section{Competing interests}

The authors declare that they have no competing interests.

\section{Consent for publication}

Patients' consent for publication was obtained in every study and can be found in the corresponding publications included in this analysis.

\section{Ethics approval and consent to participate}

Ethical clearance was obtained in every study and can be found in the corresponding publications included in this analysis. Patients' consent to participate was obtained in every study and can be found in the corresponding publications included in this analysis.

\section{Publisher's Note}

Springer Nature remains neutral with regard to jurisdictional claims in published maps and institutional affiliations.

\section{Author details}

${ }^{1}$ Independent Researcher, Mae Sot, Thailand. ${ }^{2}$ Medical Research Council Unit, Fajara, Banjul, The Gambia. ${ }^{3}$ London School of Hygiene and Tropical Medicine, London, UK. ${ }^{4}$ Institute of Tropical Medicine, Antwerp, Belgium. ${ }^{5}$ Department of Parasitology, Faculty of Medicine, Cheikh Anta Diop
University, Dakar, Senegal. ${ }^{6}$ Malaria Research and Training Center, Department of Epidemiology of Parasitic Diseases, Faculty of Pharmacy, University of Science, Techniques and Technologies of Bamako, Bamako, Mali. ${ }^{7}$ Department of Medicine, University of California San Francisco, San Francisco, California, USA. ${ }^{8}$ Department of Microbiology, Tumor and Cell Biology, Karolinska Institutet, Stockholm, Sweden. 'Department of Women's and Children's Health, International Maternal and Child Health (IMCH), Uppsala University, Uppsala, Sweden. ${ }^{10}$ Swiss Tropical and Public Health Institute, Basel, Switzerland. ${ }^{11}$ University of Basel, Basel, Switzerland. ${ }^{12}$ Special Programme for Research \& Training in Tropical Diseases (WHO/TDR), 20 Avenue Appia, 1211 Geneva, Switzerland. ${ }^{13}$ Centre for Tropical Medicine and Global Health, Nuffield Department of Medicine, University of Oxford Churchill Hospital, OX37LJ, Oxford, UK.

Received: 23 August 2016 Accepted: 6 June 2017 Published online: 23 June 2017

\section{References}

1. Perkins DJ, Were T, Davenport GC, Kempaiah P, Hittner JB, et al. Severe malarial anemia: innate immunity and pathogenesis. Int J Biol Sc. 2011;7: 1427-42.

2. Krystal JE, Hansen DS, van Rooijen N, Buckingham LA, Schofield L. Severe malarial anemia of low parasite burden in rodent models results from accelerated clearance of uninfected erythrocytes. Blood. 2006;107:1192-9.

3. World Health Organisation: Guidelines for the treatment of malaria. Third edition (2015) http://apps.who.int/iris/bitstream/10665/162441/1/9789241549127_eng.pdf. Accessed 12/01/2016.

4. Finaurini S, Ronzoni L, Colancecco A, Cattaneo A, Cappellini MD, et al. Selective toxicity of dihydroartemisinin on human CD34+ erythroid cell differentiation. Toxicology. 2010;276:128-34.

5. Rehman K, Lötsch F, Kremsner PG, Ramharter M. Haemolysis associated with the treatment of malaria with artemisinin derivatives: a systematic review of current evidence. Int J Infect Dis. 2014:29:268-73.

6. Adjuik M, Agnamey P, Babiker A, Borrmann S, Brasseur P, et al. Amodiaquineartesunate versus amodiaquine for uncomplicated Plasmodium falciparum malaria in African children: a randomised, multicentre trial. Lancet. 2002;359: $1365-72$.

7. Olliaro P, Nevill C, LeBras J, Ringwald P, Mussano P, et al. Systematic review of amodiaquine treatment in uncomplicated malaria. Lancet. 1996;348: 1196-201.

8. Sinclair D, Zani B, Donegan S, Olliaro P, Garner P. Cochrane Database Syst Rev. 2009;8:CD007483. Review

9. Sirima SB, Tiono AB, Gansane A, Diarra A, Ouedraogo A, et al. The efficacy and safety of a new fixed-dose combination of amodiaquine and artesunate in young African children with acute uncomplicated Plasmodium falciparum. Malar J. 2009;8:48

10. Gasasira AF, Kamya MR, Achan J, Mebrahtu T, Kalyango JN, et al. High risk of neutropenia in HIV-infected children following treatment with artesunate plus amodiaquine for uncomplicated malaria in Uganda. Clin Infect Dis. 2008;46:985-91.

11. Zwang J, Ndiaye JL, Djimdé A, Dorsey G, Mårtensson A, et al. Comparing changes in haematologic parameters occurring in patients included in randomized controlled trials of artesunate-amodiaquine vs single and combination treatments of uncomplicated falciparum in sub-Saharan Africa. Malar J. 2012;11:25.

12. Bethell D, Se Y, Lon C, Socheat D, Saunders D, et al. Dose-dependent risk of neutropenia after 7-day courses of artesunate monotherapy in Cambodian patients with acute Plasmodium falciparum malaria. Clin Infect Dis. 2010;51: e105-14.

13. Four Artemisinin-Based Combinations (4ABC) Study Group. A head-tohead comparison of four artemisinin-based combinations for treating uncomplicated malaria in African children: a randomized trial. PLoS Med. 2011:8:e1001119.

14. Djimdé AA, Fofana B, Sagara I, Sidibe B, Toure S, Dembele D, Dama S, Ouologuem D, Dicko A, Doumbo OK (2008) Efficacy, safety, and selection of molecular markers of drug resistance by two ACTs in Mali: am J Trop med Hyg 78:455-461.

15. Dorsey G, Staedke S, Clark TD, Njama-Meya D, Nzarubara B, et al. Combination therapy for uncomplicated falciparum malaria in Ugandan children: a randomized trial. JAMA. 2007;297:2210-9. 
16. Karema C, Fanello Cl, van Overmeir C, van Geertruyden JP, van Doren W, et al. Safety and efficacy of dihydroartemisinin/piperaquine (Artekin) for the treatment of uncomplicated Plasmodium falciparum malaria in Rwandan children. Trans R Soc Trop Med Hyg. 2006;100:1105-11.

17. Ndiaye JL, Randrianarivelojosia M, Sagara I, Brasseur P, Ndiaye I, et al. Randomized, multicentre assessment of the efficacy and safety of ASAQ - a fixed-dose artesunate-amodiaquine combination therapy in the treatment of uncomplicated Plasmodium falciparum malaria. Malar J. 2009:8:125.

18. Rwagacondo CE, Karema C, Mugisha V, Erhart A, Dujardin JC, et al. Is amodiaquine failing in Rwanda? Efficacy of amodiaquine alone and combined with artesunate in children with uncomplicated malaria Trop Med Int Health. 2004;9:1091-8.

19. Schramm B, Valeh P, Baudin E, Mazinda CS, Smith R, et al. Tolerability and safety of artesunate-amodiaquine and artemether-lumefantrine fixed dose combinations for the treatment of uncomplicated Plasmodium falciparum malaria: two open-label, randomized trials in Nimba County, Liberia. Malar J. 2013;12:250.

20. Schramm B, Valeh P, Baudin E, Mazinda CS, Smith R, et al. Efficacy of artesunate-amodiaquine and artemether-lumefantrine fixed-dose combinations for the treatment of uncomplicated Plasmodium falciparum malaria among children aged six to 59 months in Nimba County, Liberia: an open-label randomized non-inferiority trial. Malar J. 2013;12:251.

21. Martensson A, Stromberg J, Sisowath C, Msellem MI, Gil JP, et al. Efficacy of artesunate plus amodiaquine versus that of artemether-lumefantrine for the treatment of uncomplicated childhood Plasmodium falciparum malaria in Zanzibar, Tanzania. Clin Infect Dis. 2005:41:1079-86.

22. WHO. Haemoglobin concentrations for the diagnosis of anaemia and assessment of severity. Vitamin and Mineral Nutrition Information System (2011) Geneva, World Health Organization (WHO/NMH/NHD/MNM/11.1) (http://www.who.int/vmnis/indicators/haemoglobin.pdf. Accessed 12/01/2016)

23. Sagara I, Piarroux R, Djimde A, Giorgi R, Kayentao K, et al. Delayed anemia assessment in patients treated with oral artemisinin derivatives for uncomplicated malaria: a pooled analysis of clinical trials data from Mali. Malar J. 2014;13:358

24. Oguche S, Okafor HU, Watila I, Meremikwu M, Agomo P, et al. Efficacy of artemisinin-based combination treatments of uncomplicated falciparum malaria in under-five-year-old Nigerian children. Am J Trop Med Hyg. 2014; 91:925-35.

25. Bouyou-Akotet MK, Mawili Mboumba DP, Kendjo E, Mbadinga F, ObiangBekale N, et al. Anaemia and severe malarial anaemia burden in febrile Gabonese children: a nine-year health facility based survey. J Infect Dev Ctries. 2013;7:983-9.

26. Maiga $H$, Djimde AA, Beavogui AH, Toure $\mathrm{O}$, Tekete $M$, et al. Efficacy of sulphadoxine-pyrimethamine + artesunate, sulphadoxine-pyrimethamine + amodiaquine, and sulphadoxine-pyrimethamine alone in uncomplicated falciparum malaria in Mali. Malar J. 2015;14:64

27. Nambozi M, Malunga P, Mulenga M, Van Geertruyden JP, D'Alessandro U. Defining the malaria burden in Nchelenge District, northern Zambia using the World Health Organization malaria indicators survey. Malar J. 2014;13:220.

28. Nji AM, Ali IM, Moyeh MN, Ngongang EO, Ekollo AM, et al. Randomized non-inferiority and safety trial of dihydroartemisin-piperaquine and artesunate-amodiaquine versus artemether-lumefantrine in the treatment of uncomplicated Plasmodium falciparum malaria in Cameroonian children. Malar J. 2015;14:27.

29. Olliaro P, Djimdé A, Dorsey G, Karema C, Mårtensson A, et al. Hematologic parameters in pediatric uncomplicated Plasmodium falciparum malaria in sub-Saharan Africa. Am J Trop Med Hyg. 2011;85:619-25.

30. Zwang J, Dorsey G, Mårtensson A, d'Alessandro U, Ndiaye JL, Karema C, et al. Plasmodium falciparum clearance in clinical studies of artesunateamodiaquine and comparator treatments in sub-Saharan Africa, 1999-2009. Malar J. 2014:13:114

31. Jauréguiberry S, Thellier M, Ndour PA, Ader F, Roussel C, et al. French Artesunate working group. Delayed-onset hemolytic anemia in patients with travel-associated severe malaria treated with artesunate, France, 2011-2013. Emerg Infect Dis. 2015;21:804-12.

32. Brooks MH, Malloy JP, Bartelloni PJ, Tigertt WD, Sheehy TW, Barry KG Pathophysiology of acute falciparum malaria. I. Correlation of clinical and biochemical abnormalities. Am J Med. 1967 Nov:43(5):735-44.

\section{Submit your next manuscript to BioMed Central and we will help you at every step:}

- We accept pre-submission inquiries

- Our selector tool helps you to find the most relevant journal

- We provide round the clock customer support

- Convenient online submission

- Thorough peer review

- Inclusion in PubMed and all major indexing services

- Maximum visibility for your research

Submit your manuscript at www.biomedcentral.com/submit
Biomed Central 